\title{
"ATO SEM PERDÃO": JUSTIÇA DE TRANSIÇÃO, POLÍTICAS DE MEMÓRIA E REPARAÇÃO ÀS MULHERES VÍTIMAS DE VIOLÊNCIA DE GÊNERO DURANTE A DITADURA MILITAR BRASILEIRA
}

"Act without forgiveness": transitional justice, memory and repair policies for women victims of gender violence during Brazilian military dictatorship

“Acto sin perdón": justicia de transición, políticas de memoria y reparación de mujeres víctimas de violencia de género durante la dictadura militar brasileña

\author{
ADRIANNA SETEMY ${ }^{I^{*}}$
}

DOI: http://dx.doi.org/10.1590/S2178-14942020000200007

\footnotetext{
'Universidade Federal do Rio de Janeiro - Rio de Janeiro (RJ), Brasil.

*Doutora em História Social pela Universidade Federal do Rio de Janeiro. Pesquisadora de Pós-Doutorado Júnior do Centro de Pesquisa e Documentação de História Contemporânea do Brasil da Fundação Getulio Vargas (FGV CPDOC) (asetemy@gmail.com). (D) https://orcid.org/0000-0002-6213-5088
}

Artigo recebido em $1^{\circ}$ de janeiro de 2020 e aprovado para publicação em 12 de março de 2020. 
"ATO SEM PERDÃO": JUSTIÇA DE TRANSIÇÃO, POLÍTICAS DE MEMÓRIA E REPARAÇÃO ÀS MULHERES VIITIMAS DE VIOLÊNCIA DE GÊNERO DURANTE A DITADURA MILITAR BRASILEIRA

\title{
RESUMO
}

0 texto apresenta uma reflexão a respeito da necessidade de incorporar-se uma perspectiva de gênero às pesquisas dedicadas a compreender processos de violações massivas de direitos humanos, bem como sobre a violência de Estado durante a ditadura militar no Brasil. Para isso, toma como base a análise de dois casos emblemáticos de mulheres apresentados pelo relatório final da Comissão Nacional da Verdade: Zuzu Angel e Ana Kucinski. 0 objetivo é tornar visível a diferença do impacto da violência de Estado sobre mulheres e homens, bem como o silenciamento da dimensão de gênero da violência de que foram vítimas essas mulheres, dentro dos processos de justiça de transição.

PALAVRAS-CHAVE: Gênero; Mulher; Violência; Justiça de transição; Políticas de memória; Reparação.

\begin{abstract}
The following text presents a reflection on the need to incorporate a gender perspective into researches devoted to understanding processes of massive human rights violations, as well as reflections about state violence during the military dictatorship in Brazil, based on the analysis of two emblematic cases of women presented by the Final Report of the National Truth Commission: Zuzu Angel and Ana Kucinski. The objective is to make visible the different impact of state violence on women and men, as well as the silencing of the gender dimension of violence they have suffered within the transitional justice processes.
\end{abstract}

KEYWORDS: Gender; Woman; Violence; Transitional justice; Memory policies; Reparation.

\section{RESUMEN}

El siguiente texto presenta una reflexión sobre la necesidad de incorporar una perspectiva de género en la investigación dedicada a comprender los procesos de violaciones masivas de los Derechos Humanos, así como reflexiones sobre la violencia del Estado durante la dictadura militar en Brasil, a partir del análisis de dos casos emblemáticos de mujeres presentados por el Informe Final de la Comisión Nacional de la Verdad: Zuzu Angel y Ana Kucinski. El objetivo es hacer visible la diferencia en el impacto de la violencia estatal en mujeres y hombres, así como el silenciamiento de la dimensión de género de la violencia de la que fueron víctimas, dentro de los procesos de justicia transicional.

PALABRAS CLAVE: Género; Mujeres; Violencia; Justicia transicional; Políticas de memoria; Reparación. 
luta em defesa do respeito aos direitos humanos e as demandas por justiça e verdade sobre a violência e os crimes cometidos pelo Estado durante a ditadura militar brasileira (1964-1985) vêm adquirindo cada vez mais espaço na agenda política no decurso do processo de institucionalização da democracia. A justiça de transição, componente de um processo de mudança de regime cujas diferentes facetas são parte integrante desse processo incerto e excepcional, que tem lugar entre a dissolução do autoritarismo e a institucionalização da democracia, envolve uma série de medidas tomadas ao longo da redemocratização que vão além da criminalização de perpetradores, colaboradores e agentes da repressão. Os instrumentos a serviço da justiça de transição envolvem grande diversidade de esforços extrajudiciais, tais como investigações históricas oficiais, saneamentos, reparações, dissolução de instituiç̧ões legadas pelo regime anterior e comissões da verdade. No Brasil, em maio de 2012, foi instalada a Comissão Nacional da Verdade (CNV), que no decorrer de dois anos e meio procurou cumprir a tarefa estipulada pela Lei no 12.528 , de 18 de novembro de 2011, que a instituiu, de efetivar o direito à memória e à verdade histórica e promover a reconciliação nacional. Os trabalhos da CNV somaram-se aos esforços institucionais anteriores, que remontam aos anos de 1990, quando foi editada a Lei $n^{\circ}$ 9.140, de 1995, para reconhecimento da responsabilidade estatal pelos crimes cometidos pelo Estado durante a ditadura militar e instalação da Comissão Especial sobre Mortos e Desaparecidos Políticos (CEMDP), em 1996, cujas atividades resultaram na publicação do relatório Direito à memória e à verdade, em 2007. Apesar de todos os esforços da justiça de transição brasileira no intuito de registrar os fatos e esclarecer as circunstâncias dos casos de graves violações de direitos humanos praticadas entre 1964 e 1985, os relatos de violência de gênero permanecem velados, invisibilizados ou, ainda, relegados, sob caracterizações abrangentes como "violação de direitos humanos" e "terrorismo de Estado contra a sociedade civil", como evidenciam os perfis biográficos dos mortos e desaparecidos políticos, compilados no quarto volume do relatório final da CNV, bem como revelam os depoimentos orais de mulheres que sobreviveram às violências perpetradas por instituições do Estado brasileiro e seus agentes durante a ditadura militar brasileira.

Desde os anos de 1990, o debate jurídico internacional passou a definir e caracterizar violência sexual e violência de gênero no contexto de práticas sistemáticas de violência como um modo específico de violação dos direitos humanos. Em 1998, o Estatuto de Roma, que estabeleceu a Corte Penal Internacional, tipificou violência sexual e de gênero como crime de lesa-humanidade, criando condições favoráveis ao reconhecimento e denúncia desse tipo de violência como prática de tortura, bem como à apuração e elaboração de respostas jurídicas 
adequadas às suas especificidades. Considerando as mudanças promovidas no marco jurídico internacional, o objetivo principal deste artigo é refletir acerca dos avanços e limites na incorporação de uma perspectiva de gênero às pesquisas dedicadas a compreenderem processos de violações massivas de direitos humanos durante a ditadura militar brasileira, tomando como base a análise de "casos emblemáticos" de mulheres mortas e desaparecidas, então apresentados pelo relatório final da CNV. O objetivo é refletir sobre a diferença do impacto da violência de Estado sobre mulheres e homens, bem como sobre o silenciamento da dimensão de gênero da violência dentro dos processos de justiça de transição. Entende-se que o esforço para uma incorporação mais ampla da perspectiva de gênero às reflexões sobre violência institucional e de Estado poderá ter impacto nos processos e políticas de memória, justiça e reparação. Assim como o impacto da repressão foi diferente para homens e mulheres, entende-se que as políticas de memória e reparação também devem levar em conta tais diferenças e especificidades, para que sejam mais eficazes em seus objetivos.

Segundo Enzo Traverso (2007: 3), a emergência de novas questões em relação a um passado tantas vezes revisitado explica-se pelo fato de que o passado está em constante processo de reelaboração, tanto historiográfica quanto memorialística, conforme as sensibilidades éticas, culturais e políticas do presente. É nesse sentido que, no presente, a ampliação das noções e definições relativas à violência de gênero coloca na ordem do dia a necessidade de uma análise mais aprofundada dessa dimensão das violações cometidas pelos agentes a serviço da ditadura militar brasileira.

\section{MARCOS LEGAIS INTERPRETATIVOS DA VIOLÊNCIA CON- TRA AS MULHERES: ENTRE A DEFESA DOS DIREITOS HUMA- NOS E O CUMPRIMENTO DO "DEVER DE MEMÓRIA"}

pós a Segunda Guerra Mundial (1939-1945), o estupro passou a ser reconhecido como
crime em nível internacional, e até mesmo como crime contra a humanidade, embora um tratado internacional específico nunca tenha sido formulado, como aconteceu com outros crimes como genocídio, apartheid, desaparecimento forçado e tortura.

0 pleno reconhecimento do estupro como crime internacional, nos moldes que conhecemos hoje, foi o produto de conquistas relativamente recentes, resultante da forma como essa violação foi tratada nos tribunais internacionais a partir do fim dos anos de 1990, nos quais passaram a ser incorporadas e consideradas referências às circunstâncias que implicaram coerção física ou psicológica, abuso de poder ou a condição da vítima ou sobrevivente. Em 1993, o Conselho de Segurança das Nações Unidas, órgão da Organização das Nações Unidas (ONU), ao discutir a criação do Tribunal Penal Internacional para a lugoslávia, incorpo- 
rou o estupro entre suas considerações por meio da Resolução n 820, que condenava: "[...] todas as violações do direito internacional humanitário, incluindo, em particular, a prática de 'limpeza étnica', detenções e violações organizadas e sistemáticas de mulheres [...]".

Em muitos desses documentos e regulamentos, a violência sexual era interpretada como um ataque ao "pudor", à "dignidade" ou à "honra". No entanto esse paradigma vem mudando. Em 2008, o Conselho de Segurança da ONU reconheceu a violência sexual como crime de lesa-humanidade, instrumento de coerção política coletiva, portanto uma questão pública, e não apenas relacionada à moral pessoal.

Violações, nudez forçada e o toque corporal de mulheres e homens foram práticas constantemente empregadas por agentes da repressão a serviço das ditaduras militares do Cone Sul (Jelin, 2011: 1). Entretanto, o silenciamento ou a alusão explícita à especificidade de gênero da repressão vem variando ao longo do tempo, conforme as transformações dos sentidos políticos que, no presente, são atribuídos ao passado. Essas variações dos sentidos outorgados ao passado estão diretamente relacionadas ao fato de que a luta em defesa do respeito aos direitos humanos, que teve início a partir do pós-Segunda Guerra, e daí as demandas por justiça e verdade acerca da violência e dos crimes cometidos pelo Estado, engendrou a construção de um novo personagem que, desde fins da década de 1960, converteu-se em protagonista: o testemunho, enquanto encarnação do passado do qual é preciso manter a lembrança.

À "era das catástrofes" corresponde aquilo que Annette Wieviorka chamou de a "era dos testemunhos" (Seligmann-Silva, 2005: 82). Ou seja, o testemunho passou do lugar de "esquecido" ao lugar de "vítima"/"herói", e muitas vezes é colocado, seja pelas autoridades do Estado ou pelos pesquisadores, em uma posição que não escolheu e que nem sempre corresponde às suas necessidades de transmitir sua experiência. Trata-se de uma era em que não há "vencidos", e sim "vítimas", glorificadas em detrimento dos heróis, que caíram no ostracismo. Nesse sentido, Todorov (2009: 200-203) considera que a memória tem se tornado cada vez mais uma questão política, evocada de maneira ritualística enquanto "dever". Essa escalada, que Todorov e Traverso denominam, nas obras citadas, de "obsessão pela memória", tem se traduzido em uma reificação do passado que se materializa na crescente proliferação de museus, comemorações, filmes e séries televisivas. Paralelamente a esse processo de invasão do espaço público por uma memória transformada em ritual e/ou objeto de consumo, não necessariamente comprometida com uma reflexão e produção de conhecimento em torno dos traumas e das violências que evoca, o discurso sobre os direitos humanos foi consolidando-se como movimento social transnacional em diferentes partes do mundo, sobretudo nos Estados Unidos e na Europa, durante os anos de 1970, ganhando força na década de 1980 e, com as 
políticas de memória, atingiu proporções globais a partir dos anos de 1990. Segundo Andreas Huyssen (2014: 195-213), existe uma relação recíproca e intrínseca entre direitos humanos e memória, uma vez que ambos os discursos foram historicamente sobredeterminados, afinal, pergunta o autor: "Sem a memória dos campos de carnificina, onde estaria e que seria hoje os movimentos de direitos humanos?" (Huyssen, 2014: 199). É claro que sempre houve um discurso da memória, e o discurso dos direitos, em si, tem uma história mais antiga. No entanto, 0 atual movimento internacional dos direitos humanos e os fluxos transnacionais da política da memória expressam, desde a década de 1990, uma conjuntura fundamentalmente nova.

Os movimentos sociais pelos direitos humanos têm suas origens nas denúncias de genocídios e de violações de direitos fundamentais após a Segunda Guerra, no fim das ditaduras na América Latina, na queda do Muro de Berlim, no colapso da União Soviética, no fim do apartheid na África do Sul e nos massacres ocorridos na Bósnia e em Ruanda.

Logo após o término da Segunda Guerra Mundial, os relatos dos sobreviventes começaram a aparecer e a chamar a atenção do grande público, a exemplo do livro 0 diário de Anne Frank, então publicado na Holanda, em 1947, e o relato em Primo Levi, É isso um homem?, obra também publicada em 1947, na Itália.

Durante as duas primeiras décadas após o fim da Segunda Guerra, muito se produziu a respeito da história dos conflitos e muito pouco se escreveu acerca do destino dos judeus europeus. A história que se produziu na França, na Inglaterra e nos Estados Unidos era eminentemente uma "históra dos vencedores", que destacava sobretudo o papel que os Estados Unidos e os demais países aliados tiveram na vitória contra o Eixo.

A partir dos anos de 1960, com o julgamento de Adolf Eichmann, duas décadas após o fim da Segunda Guerra, a voz dos sobreviventes passou não apenas a ser ouvida, como também ganhou grande repercussão pública. Os relatos ganhavam maior carga emotiva em meio a um "espetáculo testemunhal" , com ampla cobertura da imprensa, na medida em que se reforçava a ideia de que o genocídio fora um evento judaico, não um crime contra a humanidade.

Em 1961, foram publicados os artigos que iriam compor o livro de Hannah Arendt, Eichmann em Jerusalém, publicado em 1963, no qual a autora denunciou o uso do holocausto como capital simbólico pelo Estado de Israel. Além disso, com base no depoimento de Eichmann, Arendt concluiu que este, assim como provavelmente toda a máquina burocrática do nazismo, assassinou os judeus por força de uma disciplina tipicamente alemã que os levava a cumprir mesmo as ordens que consideravam indignas, por estarem desempenhando suas obrigações enquanto burocratas, incapazes de refletir sobre seus atos ou de fugir dos clichês típicos desse carácter. Com suas reflexões sobre o caso de Eichmann, Arendt revelou o que 
seria uma ameaça às sociedades democráticas: a associação de uma capacidade destrutiva de ampla magnitude à burocratização da vida pública. Em sua análise, Arendt formulou o conceito de "banalidade do mal". Ao apresentar Eichmann como um homem médio, comum, um funcionário medíocre, e não um monstro inumano, a autora tornou-se alvo do policiamento ideológico que resultou da polarização política em torno do tema do holocausto.

Enquanto isso, a violência que caracterizou os processos de luta pela independência na Índia, Argélia, Moçambique e de consolidação de Estados como Indonésia, Uganda e Sudão raramente eram estudados e frequentemente não eram classificados como genocídios ou crimes contra a humanidade, mas caracterizados como uma espécie de "anomalia periférica".

Esse quadro historiográfico mudou nos anos de 1990, quando os eventos na lugoslávia e em Ruanda motivaram uma profusão de trabalhos sobre crimes contra a humanidade e genocídios que caracterizaram os processos de emancipação política e os períodos pós-lutas de libertação na África e na Ásia.

Os estudos sobre os genocídios pós-coloniais somaram-se aos debates acerca do holocausto, propondo uma compreensão mais ampla dos crimes contra a humanidade. Muitos institutos universitários dedicados aos estudos do holocausto foram renomeados para incluir a palavra genocídio ao lado de holocausto, ampliando sua perspectiva de pesquisa. Assim, desde o fim da década de 1990, o discurso acerca da memória e do interesse em relação aos testemunhos de vítimas vem ganhando dimensão transnacional. Em decorrência desse movimento, perpetradores de crimes contra a humanidade e genocídios, tanto na África do Sul (com o fim do apartheid e a criação paradigmática da Comissão da Verdade e Reconciliação) como na América Latina (mais especificamente na Argentina e no Chile, onde foram criadas comissões para julgar os crimes de desaparecimentos e mortes cometidos por agentes do Estado durante as últimas ditaduras militares), foram condenados tendo como referência paradigmática o holocaustro e os crimes nazistas. Dessa forma, estudos sobre memória passaram a incorporar preocupações transnacionais à medida que se tornavam cada vez mais obsoletos os paradigmas nacionais, que remontam aos estudos de Halbwachs (2008) sobre o que 0 autor denominava de "memória coletiva", ainda que as respectivas preocupações nacionais ou regionais tenham permanecido no centro dos debates transnacionais.

A guinada transnacional dos estudos sobre memória influenciou claramente as políticas nacionais de memória (criação de comissões e tribunais), os processos judiciais e os debates populares de muitos países, articulando-se de maneira vigorosa na literatura, nas artes plásticas, em filmes e documentários e até na arquitetura de museus e memoriais. Entretanto, Huyssen (2014: 210) chama atenção para um aspecto negativo da transnacionalização dos discursos de memória. Tais encontros transnacionais de lembranças traumáticas levam, com frequência, 
a competições entre as memórias, segundo o modelo "meu povo sofreu mais que o seu". Isso porque a memória, assim como a história, como forma de interpretar o passado, consiste em um campo de disputa política, como propôs Michael Pollak no texto "Memória, esquecimento, silêncio" (1989), no qual chamou atenção para os processos de dominação e submissão das diferentes versões e memórias a respeito dos passados traumáticos. Apontando para a clivagem entre memória oficial ou dominante e "memórias subterrâneas", marcadas pelo silêncio, pelo não dito, pelo ressentimento, o autor afirma que essa clivagem pode aparecer não apenas nas relações entre o Estado e a sociedade civil, como também entre a sociedade englobante e os grupos minoritários. São lembranças "proibidas", "indizíveis" ou "vergonhosas", que muitas vezes se opõem a formas mais poderosas e hegemônicas de memórias coletivas, tais como a memória nacional, ou, ainda, uma memória que reafirma hegemonias e que, portanto, resulta no silenciamento e na invisibilidade de memórias que incorporem experiências específicas.

Partindo da ideia de que os trabalhos da memória em torno dos acontecimentos traumáticos envolvem disputas de narrativas relacionadas a disputas políticas que dialogam com os interesses do presente, Andreas Huyssen afirma que o discurso dos direitos humanos, assim como as políticas de memória, deveria ligar-se de maneira mais consistente às realidades específicas, tais como as realidades regionais, locais e de gênero, tanto em termos discursivos quanto práticos. Somente assim, segundo o autor, será possível impedir que a memória, sobretudo a memória traumática, torne-se um exercício vazio, que se alimenta de si mesmo, e que o discurso dos direitos humanos converta-se em uma abstração legalista, em impecável harmonia com a democracia ocidental (Huyssen, 2014: 205-210).

Sem dúvida, os impactos da repressão das ditaduras do Cone Sul não foram os mesmos para homens e mulheres, em decorrência das posições hierárquicas diferentes que cada um ocupa no sistema de gênero. Nesse sentido, pode-se afirmar que as experiências da repressão sobre o corpo de homens e mulheres vítimas diretas de tortura, prisão, desaparecimento, assassinato e exílio não foram semelhantes por estarem vinculadas e fundamentadas no sistema de gênero predominante na sociedade como um todo.

Segundo Elizabeth Jelin, na visão dos militares, espaços públicos não eram um local legítimo para a mulher, que devia ficar restrita ao espaço privado do lar. À mulher caberia o papel de guardiã da ordem social, cuidando do marido, dos filhos e do lar, assumindo suas responsabilidades e promovendo a harmonia e a tranquilidade da família e da sociedade. Partindo desse ponto de vista, as mulheres eram consideradas culpadas por subverterem 0 que era entendido como a ordem hierárquica "natural" entre homens e mulheres. A elas eram também atribuídas a culpa pelas transgressões de seus filhos. Nessa lógica, segundo Jelin, os militares no poder apoiaram e impuseram um discurso e uma ideologia baseados em valores 
"familísticos" que, quando transgredidos, colocavam a "mulher transgressora" no papel de culpada e subversiva (Jelin, 2002: 107).

0 corpo feminino, especialmente as partes ligadas à identidade feminina (vagina, útero e seios), era objeto privilegiado dos torturadores. Para além da violação de seus corpos, quando participavam diretamente de ações políticas de resistência, as mulheres também eram torturadas por sua identidade familiar, por seu vínculo com homens - especialmente parceiros e maridos - e por seus filhos, a fim de serem obtidas informações sobre as atividades políticas em que aqueles estavam envolvidos. Portanto, o sistema repressivo afetou as mulheres no núcleo daquilo que tradicionalmente define suas identidades como mulher, mãe e esposa. Foram atingidas pela repressão não apenas em seu corpo, mas também em suas subjetividades, naquilo que constitui essencialmente suas identidades de gênero. Foram atingidas pela repressão todas aquelas que ousaram deixar a esfera privada considerada "natural", ou para atuar na resistência armada à ditadura, ou para invadir a esfera pública em busca de seus filhos desaparecidos e denunciar os crimes cometidos pelo Estado.

Os testemunhos que narram essas violações vieram à tona no âmbito da CNV. Entretanto, o que se observa é que, no conjunto, o relatório final da comissão, mesmo estando baseado em instrumentos legais internacionais que reconhecem a especificidade da violência de gênero em suas múltiplas dimensões, para além da violação corporal, e ainda que tenha dedicado um capítulo específico ao tema, naturaliza narrativas que podem ser entendidas como elementos estruturais da violência discursiva e simbólica contra a mulher.

\section{O RELATÓRIO FINAL DA COMISSÃO NACIONAL DA VERDADE E A DIMENSÃO DE GÊNERO DAS GRAVES VIOLAÇÕES DE DIREITOS HUMANOS}

I

nstalada em maio de 2012, a CNV procurou cumprir, em seus dois anos e meio de atividade, a tarefa que the foi estipulada pela Lei $n^{\circ} 12.528$, de 18 de novembro de 2011. Em suas atividades, de maio de 2012 a dezembro de 2014, a comissão empenhou-se em examinar e esclarecer o quadro de graves violações de direitos humanos praticadas entre 1946 e 1988 no Brasil, a fim de efetivar o direito à memória e à verdade histórica e promover a reconciliação nacional. Os trabalhos da CNV foram divididos em três grandes subcomissões: Pesquisa, Relações com a Sociedade e Comunicação Externa. A subcomissão de "Pesquisa, geração e sistematização de informações" foi subdividida em grupos temáticos, entre os quais o grupo de trabalho "Ditadura e gênero", que investigou as formas de violência perpetradas por agentes a serviço do Estado brasileiro que mobilizavam aspectos relacionados à feminilidade e à masculinidade como forma de abuso e dominação sobre homens e mulheres. 
No volume I do relatório, o capítulo X, intitulado "Violência sexual, violência de gênero e violência contra crianças e adolescentes", apresenta os resultados das pesquisas realizadas pelo grupo de trabalho "Ditadura e gênero". Os fundamentos para a caracterização de violência de gênero foram buscados na "Declaração Universal dos Direitos Humanos", na "Convenção Americana sobre Direitos Humanos" e na "Convenção Interamericana para Prevenir, Punir e Erradicar a Violência contra a Mulher" (Brasil, 2014a: 415-417). De acordo com o exposto ao longo do capítulo, os trabalhos de investigação realizados pela comissão, no que se refere à identificação e à caracterização da prática de violência contra a mulher exercida ou permitida por agentes de Estado, foram norteados por uma concepção mais abrangente sobre violência de gênero, para além da violência física e/ou sexual:

A violência sexual, exercida ou permitida por agentes de Estado, constitui tortura. Por transgredir preceitos inerentes à condição humana, ao afrontar a noção de que todas as pessoas nascem livres e iguais em dignidade e direitos, a normativa e a jurisprudência internacionais consideram que a violência sexual representa grave violação de direitos humanos e integra a categoria de "crimes contra a humanidade". No cumprimento de seu mandato, ao buscar promover o esclarecimento circunstanciado de casos de tortura ocorridos durante a ditadura militar, a Comissão Nacional da Verdade (CNV) pôde constatar que a violência sexual constituiu prática disseminada do período, com registros que coincidem com as primeiras prisões, logo após o golpe de Estado. Assim, este capítulo é dedicado à violência estruturada pela hierarquia de gênero e sexualidade, que busca anular a dignidade dos indivíduos violados, impedindo-os de viver como querem, de viver bem e sem humilhações. Tal violência atinge de forma diversa mulheres e homens, como mostram as investigações e os testemunhos realizados pelo grupo de trabalho "Ditadura e Gênero". (Brasil, 2014a: 400)

Segundo o relatório da CNV, violência de gênero consiste, portanto, em toda e qualquer ação que possa gerar algum tipo de discriminação pelo gênero pertencente:

Os crimes e violações de gênero, por sua vez, são aqueles cometidos contra homens e mulheres, por causa de seu sexo e/ou por causa de seus papéis de gênero, socialmente construídos. Nem sempre se manifestam sob a forma de violência sexual. Podem incluir ataques não sexuais a qualquer indivíduo, motivados por seu gênero. (Brasil, 2014a: 420)

Quanto à noção de gênero, pela qual se identifica e caracteriza essa dimensão da violência, as pesquisas realizadas pela CNV pautaram-se na seguinte concepção:

Constituídos como portadores de gênero e, em tese, livres para exercer sua sexualidade da forma como melhor thes aprouver, sobre os indivíduos recai a expectativa de que se comportem de acordo com determinados atributos e papéis resultantes de tradições socioculturais, religiosas, étnicas, de classe etc., evidenciados em papéis de gênero e "estereótipos de gênero". 
Submissão, franqueza, dependência, emoção, castidade, pudor, honra feminina, manutenção de valores, tradições familiares são alguns exemplos desses estereótipos associados à mulher "de família", seguidora de padrões socioculturais. (Brasil, 2014a: 401)

Portanto, de acordo com os termos expostos no relatório final, a CNV partia do pressuposto de que a violência de gênero praticada pelos militares não se limitou à violência sexual, de caráter físico, mas caracterizou-se também pelo emprego de violência verbal, ameaças e intimidação, humilhações e maus-tratos que visavam atingir mulheres e homens em virtude de seus papéis de gênero socialmente construídos.

No caso das mulheres, mais especificamente, muitas foram vítimas de graves violações de direitos humanos em decorrência de terem "ousado" participar do mundo político, tradicionalmente entendido como masculino, ato sem perdão, que na concepção dos militares fez com que essas mulheres deixassem de lado as funções sociais que "deveriam" ocupar "naturalmente" pela sua condição primordial de mulher, sobretudo as funções de mãe e esposa (Butler, 2011: 23). Pode-se afirmar, então, que essas mulheres sofreram duas formas distintas de punição: por seus atos e por serem mulheres.

Ainda que o relatório da CNV apresente considerações bastante abrangentes a respeito do que compreende como violência de gênero, é importante destacar que esse documento apresenta limitações no que se refere à aplicabilidade de tais concepções aos casos das vítimas de violações de direitos humanos ali reconhecidos.

0 terceiro volume do relatório foi integralmente dedicado às 434 vítimas reconhecidas, apresentando suas histórias de vida e as circunstâncias de morte ou desaparecimento. A estrutura do perfil de cada uma das vítimas foi dividida em oito partes: dados pessoais; biografia; considerações sobre o caso anteriores à instituição da CNV; circunstância da morte ou do desaparecimento; identificação do local; identificação da autoria; fontes principais de investigação e conclusões e recomendações. A CNV baseou-se nos dados já sistematizados no relatório Direito à memória e à verdade, especialmente no que se refere a dados pessoais (inclusive fotografias), biografia e circunstâncias da morte e do desaparecimento (Brasil, 2014a: 27). Além de serem textos padronizados, as informações que compõem o perfil dos mortos e desaparecidos políticos são organizadas de maneira que se possam produzir narrativas centradas na violação à integridade física das vítimas, o que resulta no silenciamento de experiências que não se ajustam aos padrões textuais e categorias de vitimização preestabelecidos.

Aplicar essa concepção ampliada de violência de gênero é fundamental para que os casos envolvendo 49 mulheres, cuja morte e desaparecimento foram reconhecidos como casos emblemáticos pelo relatório, bem como outros que por ora ainda não vieram à tona, 
possam ser compreendidos em toda a sua abrangência e complexidade, possibilitando, assim, um redimensionamento do alcance da violência praticada durante os anos da ditadura militar.

\section{A REPRESSÃO E SUAS MEMÓRIAS COMO EXPRESSÃO DAS RELAÇÕES DE GÊNERO}

$\mathrm{O}$ poder exercido pelos agentes da repressão durante a ditadura militar brasileira desenvolveu-se de acordo com o marco das relações de gênero historicamente estabelecidas. Segundo Elizabeth Jelin, no que tange às ditaduras militares do Cone Sul, a violência e a repressão tiveram especificidades de gênero que repousavam nas posições hierarquicamente distintas que mulheres e homens ocupam dentro de uma hierarquia social de gênero historicamente construída. Portanto, o impacto sofrido por mulheres e homens vítimas de violência de Estado foi diferente, ainda que ambos possam ter sido sujeitados à violência sexual e de gênero (Jelin, 2002).

Nesse sentido, pode-se afirmar que as mulheres vítimas de violência durante as ditaduras na América Latina não foram apenas as que se envolveram diretamente na resistência, por fazerem parte de ações armadas ou organizações políticas. Houve repressão e violência também contra mulheres que não estavam envolvidas com nenhuma organização de esquerda ou movimento organizado de resistência, mas que se tornaram alvo da violência de Estado pelos seus vínculos familiares, como esposas, mães, irmãs, ou avós dos mortos e desaparecidos políticos (Jelin, 2002: 100-107). Segundo María Sonderéguer e Violeta Correa, a violência exercida contra as mulheres durante as ditaduras pode ser analisada como uma situação exemplar, por meio da qual é possível observar como a estrutura de gênero reaparece, reafirmando o sistema hegemônico masculino e adequado ao próprio terrorismo de Estado, organizado pela hierarquia de gênero e sexualidade "naturalizada" no âmbito das relações sociais e de poder (Sonderéguer e Correa, 2010: 8). Em relação à identificação e caracterização da experiência vivenciada por mulheres durante as ditaduras como violência de gênero, as autoras fazem uma importante constatação: a histórica naturalização da violência contra as mulheres e o fato de o nosso imaginário a respeito da tortura ter sido construído considerando experiências eminentemente masculinas muitas vezes impedem que se identifiquem experiências vivenciadas pelas mulheres como tortura ou violação de direitos (Sonderéguer e Correa, 2010: 6).

Ainda são poucas as produções acadêmicas que incorporam a perspectiva de gênero à pesquisa de violações massivas aos direitos humanos em situações de conflito armado e em processos repressivos internos, tanto na América Latina como também em outras partes do mundo. Ainda mais escassas são as produções que partem de uma caracterização mais 
abrangente de violência de gênero, que não esteja limitada à prática da violência física ou sexual (Sonderéguer e Correa, 2010: 6). Quanto ao relatório final da CNV, embora o capítulo 10 ("Violência sexual, violência de gênero e violência contra crianças e adolescentes") do volume I apresente uma importante contribuição no reconhecimento da dimensão de gênero da violência praticada pelo Estado durante a ditadura militar, é preciso avançar na incorporação dessa perspectiva às análises sobre terrorismo de Estado, o que significa, sobretudo, considerar a diferença da natureza, da abrangência e, consequentemente, do impacto da repressão sobre as mulheres. Isso se evidencia no terceiro volume do relatório, que traz a história de vida e as circunstâncias da morte de 434 mortos e desaparecidos, entre os quais 49 eram mulheres. No texto, buscou-se a padronização das conclusões sobre os casos, identificando as graves violações de direitos humanos praticadas, tais como prisão ilegal e arbitrária, tortura, morte ou desaparecimento forçado, sem fazer qualquer consideração em relação às possíveis violações em decorrência das funções sociais que desempenhavam pela sua condição primordial de mulher (Sonderéguer e Correa, 2010). Para evidenciar tal afirmação, tomaremos dois casos emblemáticos: Zuzu Angel e Ana Rosa Kucinsk/Ana Rosa Silva. ${ }^{1}$

Zuleika Angel, conhecida como Zuzu Angel, foi casada com Norman Angel Jones, com quem teve três filhos, Stuart Edgar Angel Jones, Ana Cristina Angel Jones e Hildegard Beatriz Angel Jones. No início da década de 1970, a vida de Zuleika Angel Jones sofreu uma reviravolta, pois, em 1971, seu filho Stuart Angel Jones, militante no Movimento Revolucionário 8 de Outubro (MR-8), foi sequestrado por gentes da repressão e nunca mais visto, desde o dia 14 de maio daquele ano. Todas as iniciativas de Zuzu contribuíram para o desgaste da imagem internacional da ditadura brasileira, o que causava incômodo nos meios governamentais.

Zuleika Angel Jones morreu na madrugada do dia 14 de abril de 1976, em acidente automobilístico na saída do Túnel Dois Irmãos, na Estrada da Gávea, no Rio de Janeiro. Tendo em vista as várias ameaças anônimas recebidas pela estilista, em virtude de sua insistente luta por informações do paradeiro de seu filho Stuart, logo surgiu a desconfiança de que o acidente teria sido provocado por agentes dos órgãos repressivos.

No volume III do relatório da CNV, o perfil dedicado a Zuzu Angel apresenta uma conclusão abrangente:

Diante das investigações realizadas, conclui-se que Zuleika Angel Jones morreu em decorrência de ação perpetrada por agentes do Estado brasileiro, em contexto de sistemáticas violações de direitos humanos promovidas pela ditadura militar, implantada no país a partir de abril de 1964. (Brasil, 2014b: 1.841) 
Contudo, o principal campo do perfil, no qual são descritos as circunstâncias de sua morte, apresenta evidências da especificidade de gênero da violência sofrida por Zuzu Angel desde o desaparecimento de seu filho.

Considerando os apontamentos feitos pelas autoras Sonderéguer e Correa, a dificuldade em se entender casos como o de Zuzu Angel como violência de gênero explica-se pelo fato dela não ter sofrido violência sexual nem ter sido torturada fisicamente. Nesse sentido, pode-se pensar que o assassinato de Zuzu Angel foi o último grau de violência a que esteve exposta desde que passou a ocupar espaço público em busca do paradeiro de seu filho desaparecido, tornando-se alvo dos militares. A motivação desse ato final de violência está diretamente relacionada à sua condição de mulher, mãe de um "subversivo", que desafiou a ordem social patriarcal defendida pelos militares. Além disso, Zuzu Angel era uma mulher independente, que tinha sua carreira de estilista de moda, na qual se destacou internacionalmente e por meio da qual denunciou os crimes da ditadura militar brasileira. Tudo isso fez de Zuzu um alvo da violência do Estado contra as mulheres que subvertiam o papel que a elas era tradicionalmente designado, a de protagonistas do espaço privado do lar. Historicamente, o homem permeia o espaço público, enquanto a mulher, o privado; sendo assim, quando uma mulher sai do espaço que the é reservado e se coloca na esfera pública, ocasiona determinada descriminação e consequentemente algum tipo de violência. Nas palavras de Simone de Beauvoir: "se as dificuldades são mais evidentes na muIher independente é porque ela escolheu não a resignação e sim a luta" (Beauvoir, 1967: 456).

0 relatório final da CNV apresenta evidências de que Zuzu Angel foi vítima de uma visão estereotipada de gênero, presente, por exemplo, na versão oficial para o acidente de carro em que a estilista morreu:

A versão divulgada à época foi a de que o carro de Zuleika Angel Jones, um Karman Ghia, teria saído da pista, colidido com a proteção do viaduto Mestre Manuel e capotado várias vezes em um barranco. A certidão de óbito, assinada pelo médico Higino de Carvalho Hércules, confirmou a versão do acidente e atestou como causa da morte uma "fratura do crânio com hemorragia subdural e laceração cervical". Chegou-se a cogitar que a estilista tivesse ingerido bebida alcoólica e, por isso, perdido o controle do veículo. Essa possibilidade foi logo descartada após o exame toxicológico, que atestou a ausência de álcool em seu sangue. Noticiavam, também, a fadiga da motorista, que poderia ter adormecido no volante. (Brasil, 2014b: 1.837)

De acordo com as considerações sobre violência de gênero apresentadas no primeiro volume do relatório, dentro do sistema masculino e patriarcal, mulheres são consideradas mais frágeis e suscetíveis a acidentes em relação aos homens.

0 relatório da CNV ainda faz referência ao caso de Zuzu Angel nos volumes I e III. No volume I, o caso é tratado na parte IV, capítulo 13, parte D, em que discute a "Violência e terrorismo 
de Estado contra a sociedade civil". No volume III, o caso de Zuzu é um dos que compõe a seção dedicada aos "Mortos e desaparecidos políticos". Portanto o relatório da CNV não trata o caso de Zuzu Angel em sua totalidade. Classificando-o como violação de direitos humanos e terrorismo de Estado, restringe-se a explicitar a dimensão da violência empregada na ação de agentes do Estado que resultou em sua morte. Toda a trajetória de Zuzu Angel, desde o momento em que inicia a busca pelo paradeiro do filho, serve apenas como enredo de uma narrativa que está orientada no sentido de caracterizar o desfecho da história, sua morte, como ação planejada e executada por agentes do Estado. Entretanto, o sistema repressivo atingiu Zuzu Angel muito antes, sendo vítima de graves violações de direitos durante todos os anos em que esteve à procura de seu filho, torturada em razão de seu papel familiar de mãe, a quem foram negadas informações sobre o paradeiro do filho e a quem atribuíram a culpa por seus maus caminhos e "desvios subversivos".

Ao longo do ensaio Diante da dor dos outros, Susan Sontag (2003) afirma que as obras de arte têm a capacidade de treinar nossa imaginação para reconhecer "a dor alheia", as violações de direitos a que o outro é submetido. Assim como em Antígona, de Sófocles, tragédia grega que diz respeito não apenas às obrigações para com os mortos, mas também aos direitos dos vivos em relação à memória de seus mortos, na canção "Angélica" o compositor Chico Buarque não apenas reconheceu a dor de Zuzu Angel, a quem dedicou a canção, ao longo da busca pelo filho desaparecido:

Quem é essa mulher

Que canta sempre esse estribilho?

Só queria embalar meu filho

Que mora na escuridão do mar

Quem é essa mulher

Que canta sempre esse lamento?

Só queria lembrar o tormento

Que fez meu filho suspirar

Quem é essa mulher

Que canta sempre o mesmo arranjo?

Só queria agasalhar meu anjo

E deixar seu corpo descansar

Quem é essa mulher

Que canta como dobra um sino?

Queria cantar por meu menino

Que ele já não pode mais cantar².

Com sua obra de arte, Chico Buarque foi capaz de construir e oferecer uma forma de reparação simbólica que o relatório final da CNV, enquanto instrumento jurídico, não logrou alcançar. 
Nascida em São Paulo, Ana Rosa Kucinski era filha de judeus poloneses que imigraram para o Brasil na primeira metade do século XX. Nos primeiros anos da década de 1960, Ana Rosa iniciou seus estudos na Universidade de São Paulo (USP), onde concluiu a graduação em química no ano de 1967. Na mesma época, conheceu o físico Wilson Silva, com quem se casou no dia 11 de julho de 1970. Tornou-se professora do Instituto de Química da USP. Despareceu no dia 22 de abril de 1974, aos 32 anos, na companhia de seu marido, Wilson Silva, em São Paulo. Em outubro de 1975, foi demitida pelo Instituto de Química por abandono de emprego.

No volume III do relatório da CNV, o perfil dedicado a Ana Rosa Kucinski apresenta uma conclusão abrangente: "Diante das investigações realizadas, conclui-se que Ana Rosa Kucinski/Ana Rosa Silva desapareceu em 22 de abril de 1974, em contexto de sistemáticas violações de direitos humanos promovidas pela ditadura militar, implantada no país a partir de abril de 1964". Contudo, assim como no caso de Zuzu Angel, o principal campo do perfil, no qual são descritos as circunstâncias de sua morte, apresenta evidências da especificidade de gênero da violência sofrida por Ana Kucinski, mesmo após seu desaparecimento (Brasil, 2014b: 1.652).

No livro Memórias de uma guerra suja, publicado em 2012, o ex-delegado da Polícia Civil do Espírito Santo, Cláudio Guerra, afirmou ter participado da incineração de corpos de presos políticos na Usina Cambahyba, em Campos dos Goytacazes, Rio de Janeiro, que pertencia ao ex-deputado federal e ex-vice-governador do estado do Rio de Janeiro, Heli Ribeiro Gomes. A CNV realizou perícia no local e, ainda que não tenha sido possível encontrar evidências concretas do uso de fornos para os fins declarados por Cláudio Guerra, verificou-se a plausibilidade de seus relatos em razão de dois elementos principais: o tamanho dos fornos e a data de sua construção, no ano de 1974. Sobre Ana Rosa Kucinski e Wilson Silva, Cláudio Guerra afirmou:

Eu me lembro muito bem do casal, Ana Rosa Kucinski e Wilson Silva, por conta de um incidente no caminho entre a rua Barão de Mesquita e a usina. Eu e o sargento Levy, do DOI, fomos levar seus corpos. [...] Não havia perfuração de bala neles. Quem morre de tiro não sofre. Morte por tortura é muito mais desumano. Eu não prestava muita atenção nos cadáveres que transportava. Até porque eles nos eram entregues dentro de um saco. 0 problema é que, quando estávamos indo do Rio em direção a Campos, já quase chegando lá, bem naquela reta da estrada, o Chevette que viajávamos simplesmente pegou fogo. Os corpos do casal não tinham sido afetados pelo incêndio do carro. 0 que fizemos? Simplesmente saímos do veículo. Naquela época não havia celular, era tudo mais difícil. 0 sargento Levy pegou carona até um telefone público, ligou para a usina [Usina Cambahyba] e eles vieram nos resgatar na estrada. (Brasil, 2014b: 1.837) 
Desde o desaparecimento de Ana Rosa Kucinski, em 22 de abril de 1974, o Estado brasileiro posicionou-se de diferentes maneiras diante das denúncias dos familiares, recusando-se, a princípio, a fornecer qualquer informação em decorrência do não reconhecimento da prisão do casal de militantes. Ao longo dos anos, diferentes versões foram divulgadas para o desaparecimento de ambos. Apesar da impossibilidade de conseguir informações seguras, as famílias insistiram na luta pelo direito de saber o que havia acontecido com Ana Rosa e Wilson Silva.

Em depoimento prestado à Comissão Nacional da Verdade (CNV) no dia 30 de outubro de 2012, Marival Chaves Dias do Canto declarou que Ana Rosa Kucinski e Wilson Silva foram levados à Casa da Morte ainda vivos. No dia 10 de maio de 2013, prestou outro depoimento à CNV, em que afirmou que Ana Rosa, Wilson e outros militantes da Aliança Libertadora Nacional foram presos após delação do agente infiltrado João Henrique Ferreira de Carvalho, o "Jota", que depois passou a atuar como médico em Brasília. Em novo depoimento prestado à CNV em 7 de fevereiro de 2014, Marival confirmou que Ana Rosa e Wilson foram levados para Petrópolis pelo coronel do Exército Freddie Perdigão Pereira.

Segundo o depoimento de Marival Chaves Dias, Ana Rosa Kucinski e Wilson Silva foram presos em São Paulo e levados à Casa da Morte, em Petrópolis, ainda vivos, pelo coronel do Exército Freddie Perdigão Pereira.

Quando agentes do Estado narram suas memórias da repressão, as referências que fazem à tortura e à prisão estão fortemente marcadas pela centralidade do corpo das vítimas, mesmo nos casos de desaparecidos cujo corpo foi ocultado. A possibilidade de incorporar suas narrativas ao campo das memórias sociais pode ser vista como uma forma simbólica de reconhecer publicamente a responsabilidade do Estado pela prisão e desaparecimento do casal Ana e Wilson, cujos corpos, segundo seu testemunho, foram ocultados e eliminados com o uso de fornos da Usina de Cambahyba, em Campos dos Goytacazes. Entretanto, ao tornarem públicas suas narrativas memorialísticas, esses agentes revelam que o terrorismo de Estado e a repressão violaram a intimidade desses corpos, pelos quais os familiares ainda hoje buscam, como evidencia o trecho a seguir, extraído do testemunho de Cláudio Guerra à CNV:

Os dois estavam completamente nus. A mulher apresentava muitas marcas de mordida no corpo, talvez por ter sido violentada sexualmente. 0 jovem não tinha as unhas da mão direita. Tudo levava a crer que tinham sido torturados. (Brasil, 2014b: 1.837)

Ao apresentar detalhes sobre o corpo de Ana e Wilson, o agente do Estado traz a público evidências de que a repressão violou a integridade e a intimidade desses indivíduos. O paradoxo está no fato de que, ao tornar pública essa violação, por meio de narrativas memorialísticas dos perpetradores, os únicos que tiveram a oportunidade de ver e criar repre- 
sentações dos corpos ocultados por agentes do Estado, esses corpos, que não puderam ser velados e enterrados, parecem continuar sendo violados ainda hoje.

Os rituais de morte, enquanto marcos civilizacionais, são necessários por possibilitar aos vivos confrontarem-se com a putrefação do corpo daquele que morreu, objeto para sempre perdido. Enquanto se despedem daquele que morreu, os vivos ainda mantêm um diálogo com a representação do objeto perdido, que deverá ser enterrado antes que o odor da decomposição invada o real e corrompa essa representação, que as poucos vai sendo ressignificada ao longo do ritual de despedida. 0 enterro do corpo é o marco da interrupção desse diálogo. No entanto, a política de ocultamento de corpos promovida pelos militares durante a ditadura tirou dos familiares das vítimas da repressão a possibilidade de interromper esse diálogo. 0 diálogo permanece enquanto os desaparecidos não são revelados.

No caso da desaparecida política Ana Kucinski, a evidência da tortura e das violações que vêm à tona com os testemunhos dos agentes de Estado nas audiências da CNV não significou a possibilidade de interrupção do diálogo de seus familiares com a jovem. Ao contrário, é uma forma de atualização das violações ao corpo da vítima, não mais enquanto materialidade, mas enquanto representação, uma vez que mesmo ocultado se torna objeto das disputas de narrativas memorialísticas relacionadas a interesses construídos no presente.

A invasão do espaço público por uma memória transformada em ritual e/ou objeto de consumo não corresponde, contudo, a um compromisso com o apaziguamento do sofrimento dos familiares, tampouco com uma reflexão em torno dos traumas e das violências que evoca. 0 desafio do historiador diante dos abusos de memória que caracterizam a "era do testemunho" está em definir possíveis abordagens para esse passado traumático que contribuam para o fortalecimento da vida democrática e o respeito às identidades.

Os casos de Zuzu Angel e de Ana Kucinski são representativos de que os depoimentos dados no âmbito da CNV evidenciam um nítido contraste entre homens e mulheres no que diz respeito à execução, vivência e memória da tortura. Portanto, mais que vítimas de violência política e de terrorismo de Estado, essas duas mulheres foram, e continuam sendo, vítimas de violência de gênero, uma vez que o impacto da repressão sobre elas foi diferente do impacto sobre os homens, tanto no que tange às experiências vividas como à sua posterior representação narrativa.

0 desafio histórico que fica a partir dessas reflexões é retomar o relatório final da CNV, enquanto fonte histórica, e replicar a pergunta feita por Chico Buarque na canção "Angélica": quem são as mulheres reconhecidas como vítimas de violações de direitos humanos? Ressignificar suas experiências a partir de uma caracterização mais abran- 
gente de violência de gênero significa as múltiplas faces de suas dores e reconhece-las enquanto sujeitos que tem direito à integridade física e também direito à sua identidade, uma vez que a violência contra a mulher, ontem e hoje, não se restringe ao ato em si, mas se prolonga através das narrativas que são dadas a essas experiências. Entendo que somente assim será possível, no presente, pensar políticas públicas e instrumentos jurídicos que sejam realmente capazes de reparar e deter a perpetuação da violência contra seus corpos e suas subjetividades.

\section{NOTAS}

1 Em 1996, o irmão de Ana Rosa, o senhor Bernardo Kucinski, solicitou à CEMDP que o nome de sua irmã fosse registrado de duas formas, com seu nome de solteira (Ana Rosa Kucinski/Ana Rosa Silva) e com seu nome de casada (Ana Rosa Silva).

2 No ano de 1985, em entrevista para a Rádio Atividade, de São Paulo, Chico Buarque falou sobre o caso de Zuzu Angel: "Eu conheci muito a Zuzu. Ela foi uma mulher que durante anos, depois da morte do filho (Stuart Angel Jones, preso político em 1971), não fez outra coisa senão se dedicar a denunciar os assassinos do filho, a reivindicar o direito de saber aonde é que estava o corpo dele. Ela ia de porta em porta mesmo. E lá em casa ela ia com muita frequência, como em outras casas também. Ela sabia, inclusive, das ameaças que pairavam sobre ela e dizia que tinha certeza que se alguma coisa acontecesse com ela a culpa seria dos mesmos assassinos do filho, que ela citava nominalmente. Na manhã do dia em que aconteceu o acidente com ela, ela tinha estado lá em casa e deixado as camisetas que ela fazia, gravadas com aqueles anjinhos que eram a marca dela, para as minhas três filhas. Aquilo me chocou muito. Ela passava em casa quase semanalmente, mostrando os relatórios todos do trabalho que ela estava fazendo aqui e nos Estados Unidos - porque afinal, o pai do Stuart era americano - , então ela tinha contato com senadores americanos, inclusive alguns dos quais me lembro até hoje, como o Frank Church, o Mondale, que era um dos senadores com quem ela contava - nunca contou com o Reagan, evidentemente... Ela tinha, inclusive, na lista dela, uma relação das posições políticas dos senadores e tinha até alguns 'ultraconservatives' que, por se tratar de um filho de cidadão americano, eram simpáticos ao clamor de mãe dessa mulher. Ela chegou a entregar a documentação ao Kissinger pessoalmente, se não me engano, no Hotel Sheraton, quando ele esteve aqui. Clandestinamente ela furou o bloqueio e, um pouco depois, the entregou uma pasta com os documentos todos que ela tinha e distribuía entre as pessoas em quem confiava, gostava. Ela morreu um pouco depois disso". (Disponível em: http://www.chicobuarque.com.br/ letras/notas/n_angelica.htm. Acesso em: 1 mar. 2020). 


\section{REFERÊNCIAS BIBLIOGRÁFICAS}

ARENDT, H. Eichmann em Jerusalém. Um retrato sobre a banalidade do mal. Rio de Janeiro: Companhia das Letras, 1983.

BEAUVOIR, S. O segundo sexo: a experiência vivida. 2. ed. Tradução de Sérgio Milliet. São Paulo: Difusão Europeia do Livro, 1967.

BRASIL. Secretaria Especial dos Direitos Humanos. Comissão Especial sobre Mortos e Desaparecidos Políticos. Direito à verdade e à memória: Comissão Especial sobre Mortos e Desaparecidos Políticos. Brasília, DF: Secretaria Especial dos Direitos Humanos, 2007.

. Lei $n^{\circ} 12.528$, de 18 de novembro de 2011. Cria a Comissão Nacional da Verdade no âmbito da Casa Civil da Presidência da República. Diário Oficial da União, Brasília, DF, 18 nov. 2011.

. Lei n 9.140, de 4 de dezembro de 1995. Reconhece como mortas pessoas desaparecidas em razão de participação ou acusação de participação em atividades políticas, no período de 2 de setembro de 1961 a 15 de agosto de 1979, e dá outras providências. Diário Oficial da União, Brasília, DF, 5 dez. 1995.

. Comissão Nacional da Verdade. Relatório. Brasília, DF: CNV, 2014a. p. 653- 659. (Relatório da Comissão Nacional da Verdade, 1).

Comissão Nacional da Verdade. Mortos e desaparecidos políticos. Brasília, DF: CNV, 2014b. p. 1.836-1.841. (Relatório da Comissão Nacional da Verdade, 3).

ANGÉLICA. Intérprete: Chico Buarque. Compositores: Miltinho e Chico Buarque. In: Almanaque. Rio de Janeiro: Ariola, 1981.

BUTLER, J. Vidas precárias. Contemporânea - Revista de Sociologia da UFSCar, São Carlos, v. 1, n. 1, p. 1333, 2011.

CONSELHO DE SEGURANÇA DAS NAÇÕES UNIDAS. Resolução nº 820, de 17 de abril de 1993.

FRANK, A. O diário de Anne Frank. São Paulo: LeBooks Editora, 2017.

GUERRA, C.; NETTO, M.; MEDEIROS, R. Memórias de uma guerra suja. Rio de Janeiro: Topbooks, 2012.

HALBWACHS, M. A memória coletiva. São Paulo: Centauro, 2008.

HUYSSEN, A. Os Direitos Humanos Internacionais e a política da memória: limites e desafios. In:

Culturas do passado-presente: modernismo, artes visuais, políticas da memória. Rio de Janeiro: Contraponto, 2014. p. 195-213.

JELIN, E. El género en las memorias. In: . Los trabajos de la memoria. Madrid: Siglo XXI, 2002. p. 99-115.

Subjetividad y esfera pública: el género y los sentidos de familia en las memorias de la represión. Política y Sociedad, Madrid, v. 48, n. 3, p. 555-569, 2011. https://doi.org/10.5209/rev_POSO.2011.v48.n3.36420.

Las múltiples temporalidades del testimonio: el pasado vivido y sus legados presentes. Clepsidra Revista Interdisciplinaria de Estudios sobre Memoria, Buenos Aires, v. 1, n. 1, p. 140-163, 2014.

LEVI, P. É isso um homem? Rio de Janeiro: Rocco, 1989. 
ROMA. Estatuto da Corte Penal Internacional, de 17 de julho de 1998. Roma, 17 jul. 1998.

POLLAK, M. Memória, esquecimento, silêncio. Revista Estudos Históricos, Rio de Janeiro, v. 2, n. 3, p. 3-15, 1989.

SELIGMANN-SILVA, M. Testemunho e a política da memória: o tempo depois das catástrofes. Projeto História Revista do Programa de Estudos Pós-Graduados de História, São Paulo, v. 30, p. 71-98, jun. 2005. Disponível em: <https://revistas. pucsp.br/revph/article/view/2255/1348>. Acesso em: 1 mar. 2020.

SONDERÉGUER, M.; CORREA, V. Violencia de género en el terrorismo de Estado: políticas de memoria, justicia y reparación. 1 ed. Bernal: Universidad Nacional de Quilmes, 2010.

SONTAG, S. Diante da dor dos outros. Rio de Janeiro: Companhia das Letras, 2003.

TODOROV, T. Los abusos de la memoria. Cartaphilus, Murcia, v. 5, p. 200-203, 2009.

TRAVERSO, E. Historia y memoria. Notas sobre un debate. In: FRANCO, M.; LEVIN, F. (orgs.). Historia reciente. Perspectivas y desafíos para un campo en construcción. Buenos Aires: Paidós, 2007. p. 67-96. 